\title{
Research on the Value of Chinese Traditional Culture to Local EAP Model Construction
}

\author{
Zihan Huang ${ }^{1, a}$ and Guangli Luo ${ }^{1, b, *}$
}

\author{
${ }^{1}$ School of business administration, guangdong university of foreign studies south china business college, guangzhou, \\ guangdong, China

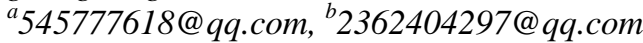 \\ *Corresponding author
}

\begin{abstract}
EAP originated from the west, most of which is western thinking. The development in China has the necessity of localization, and the psychological philosophy contained in the traditional Chinese culture represented by Chinese Confucianism, Buddhism and Taoism is extremely helpful to the localization of EAP. As for the research on the localized application of EAP in China, both the theoretical system and specific methods are still being explored, and no localized system has been formed in China. Therefore, it is an urgent task to introduce EAP into Chinese enterprises and strengthen the research on the local application of EAP. Chinese traditional culture is similar to EAP, which is a major breakthrough in the localization of EAP. This article will discuss its research value with classics.
\end{abstract}

Keywords: EAP, Chinese characteristics, Wang yangming, psychology, Buddhism, Taoism, traditional culture

\section{中国传统文化对本土 EAP 模式建设的价值研究}

\author{
黄梓瀚 ${ }^{1, \mathrm{a}}$, 罗光丽 $1, \mathrm{~b}, *$
}

1 管理学院, 广东外语外贸大学南国商学院, 广州, 广东, 中国

a545777618@qq.com, ${ }^{b 2} 262404297 @ q q . c o m$

*通讯作者

\section{摘要}

EAP 源于西方, 在其中多为西方思维。在中国的发展有本土化的必要性, 而中国儒释道三家所代表的 中国传统文化其中所蕴含的心理学哲理，则极其有助于 EAP 的本土化。国内 EAP 应用相对较少,未能 够形成完善的研究体系,EAP 整体处于摸索应用状态,难以短时间内形成较好的体系。所以,EAP 在中国 本土化运用的研究, 无论从企业角度, 还是在传统文化角度均具有较大的意义。中国传统文化则与 EAP 有异曲同工之处，是 EAP 本土化的一个重大突破口。本文将以古典论述其研究价值。

关键词: EAP，中国特色，王阳明心学，佛教心理学，道家心理学，传统文化

\section{1. 序}

\section{1. 研究背景}

$\mathrm{EAP}$ 这个名词最近几年才在国内响亮起来。那么 EAP 是 什么?EAP(Employee Assistance Program)即员工帮助计划, 企业通过 $\mathrm{EAP}$ 管理，能够为员工提供体系化的心理健康 管理;EAP 管理过程中通过其内部完善的专家指导系统， 可为员工提供整套的、科学的心里诊断, 进一步了解及 调整员工心理健康问题, 进而改善企业内部员工工作环 境及工作氛围。【1】我国近几年对外开放政策的实施, 尤其 “一带一路” 政策下进一步加强了与国外先进思想 的交流， EAP 的管理理念及管理模式正逐渐渗入到我国。
与此同时, EAP 已经经过西方先进思想及实践的考验, EAP 的引入是我国企业管理的必经之路。尤其近几年中 国经济的飞速发展, 越来越多的企业意识到员工心理健 康的重要性, EAP 先进的管理模式及科学的管理方法逐 渐受到中国诸多企业的重视。现阶段, 虽然 EAP 的引入 并应用已见成效，但 EAP 在中国仍处于 “舶来品” 的状 态, 仍是拿来主义, 其效度仍然不高。【2】国内学者对 EAP 运用的研究主要集中在其定义、适用范围、运用形 式等方面, 仍然未形成体系化的研究。而在我国企业 EAP 运用管理上, 更多情况下是直接引入国外的 EAP 体 系, 并未针对国内企业具体情况及员工心理健康程度进 行调整,因此 EAP 的运用针对性不足。因此，现阶段我 国 EAP 的运用体系化程度不足，尤其在应用方法上仍然 不够灵活，未能够基于我国国情制定体系化的 EAP 运用。 
古代典籍并以此的出经典案例与共同之处，经过汇总所 得文献数据用于研究借鉴。

\section{2. 探究}

EAP 很早便在西方发达国家得到较好的运用, 逐渐成为 西方发达国家企业治理员工心理健康的一种体系化的治 疗标准。【3】随着经济全球化及信息化的不断发展, EAP 的良好管理效果逐渐得到国内企业重视, 诸多企业 也逐渐引入 EAP 管理模式, 但更多情况下处于模仿、照 搬阶段。与西方发达国家相比, 我国具有悠久的历史文 化沉淀，同时我国国情及我国企业运营模式均与西方发 达国家有着巨大的不同, EAP 是否能够完全照搬运用仍 然需要进一步探讨。据专业研究报告指出, 当人均 GDP 在 1000-3000 美元之间时, 容易引起经济秩序、资源分 配、贫富不均、收入不稳定等现象, 现阶段我国正处于 这一不稳定阶段之中。【4】在这种情况下, 虽然 EAP 的引入能够为解决我国企业员工心理健康问题提供一定 的方式方法, 但仍然需要基于我国国情及企业内部现状 进行调整和优化。

许多的 EAP 咨询机构看好中国这块市场, 意欲在中国市 场发力, 其中不乏一些国际著名咨询机构, 但在实践的 过程中, 他们发现, 照搬西方 EAP 模式并不能适应中国 的企业情况, 1EAP 要想在中国落地, 必须进行中国化 的改良。【5】在此背景下, 作为国内唯一提倡中国化管 理的专业权威咨询机构的北京爱维龙媒咨询集团, 通过 多年来对 EAP 和中国传统哲学思想的研究, 首先提出了 $\mathrm{EAP}$ 服务应该纳入企业文化建设范畴, 同时提出, EAP 的实质其实就是员工幸福力的构建, 中国员工的辅助一 定要从精神和文化价值来开始, 而不是从心理辅导开始, 这样才能避免 EAP 与中国人的传统文化相冲突。

\section{3. 研究目的}

通过对 EAP 概念、作用形式、运用效果等内容的整理, 分析 EAP 在我国企业运用的可行性,提高 EAP 在我国企 业心理健康管理的重视程度,进而帮助我国企业进一步推 广EAP 管理体系。本研究突破传统仅以理论分析形势进 行的 EAP 研究运用, 研究过程中结合我国传统文化特点、 我国企业管理模式及员工心理健康程度现状, 提出 EAP 体系在我国企业员工心理健康管理的体系, 进一步指导我 国企业合理运用在 EAP 管理, 进一步实现 EAP 在国内企 业的转化运用, 进而对推进我国企业运用 EAP 体系管理 具有重要意义。

\section{4. 研究方法}

为了在中国传统文化对本土 EAP 模式建设的价值研究中 获得更多有用的数据我们用了多种调查方法, 包括有: 纸质 问卷调查法与网络调查法相结合、实地调查法、抽 样调查方法、统计调查方法。我们以独立院校中的 EAP 工作为背景, 做了一系列的对学生的统计调查, 所得数 据将全部用于研究的参考数据。并且我们借鉴了大量的

\section{1. 做了什么}

EAP 是新的体系、新的概念, 可能无法溯源。但 EAP 背 后的本质是什么? 它是通过是什么来支撑它这个概念体 系的? 从研究中可知它是心理学。【6】我们有五千年的 文化, 我们有五千年的古代文学, 这当中孔子、墨子、 孟子、告子, 荀子、韩非、董仲舒、王充、刘劭、范缜、 王安石、二程, 程卧、朱喜、王守仁等, 一群人都被称 为心理学人物。【7】可以说心理学在中国的文化底蕴是 很厚的。如果从这些名家的文学入手, 去发掘适合中国 人自己的 EAP 模式, 这样对于 EAP 在中国的应用无疑 是一件莫大的好事。

中国古代三大教派儒、释、道, 都有一个共同之处, 专 攻心术。心理学的中国古代应用不免会想起一个人一一 王阳明, 一位创造了心学的先贤。他的思想代表了儒家 的心理学主张。他的 “心学” 唤醒人的自我意识, 提倡 解放个性, 其核心就是, 致良知、知行合一、心外无物 的思想。我们可以从王阳明的心学里面提炼出很多可以 用于 EAP 的观点宋代哲学家陆九渊提出 “心即理也” , 以及 ‘宇宙即是吾心, 吾心即是宇宙” 的思想。王阳明 还说过: “你未看此花时, 此花与汝心同归于寂。你看 此花时, 则此花颜色一时明白起来。”【8】王阳明与朋 友同游, 朋友指着岩石间的一朵花问道: “你不是说心 外无物吗? 你看这朵花在深山中自开自落, 与我的心有 什么关系呢? ”王阳明没有正面回答这个问题, 而是做 了一个很巧妙的回答, 就是 “你未看此花时, 此花与汝 心同归于寂。你看此花时, 则此花颜色一时明白起来。” 你没看见花时, 感觉不到花, 花就不存在了; 当你看见 花时, 感觉到了, 花就存在。世间万物, 只有你看到了, 你的心才能感受到, 于你来说才是真实存在。其实不是 环境的客观变化, 而是看待客观环境的情绪变化。如果 把这个观点引入 EAP 的实践中, 给员工或者学生或者其 他成员灌输这一个观点, 那么他们看待事物的时候会不 会又有很大的改变呢? 在本校, 建立了一个心理救助 站一一禾田姆心灵家园。从建立起, 就连续有求助者, 在咨询的案例中, 不难发现一个共同点, 这些人过于追 求外部环境的完美, 希望环境能改变, 从而当遇到环境 不换, 社交不顺, 产生矛盾的时候, 心理情绪总是被环 境带着走, 心随境转, 环境有一点不好, 情绪就来抱怨、 烦恼、失落严重者甚至会走向极端。

\section{2. 调查方法}

通过匿名问卷调查, 发现了一下情况: 


\section{是否有过当情绪不好时，遇到的都是 不顺的事}

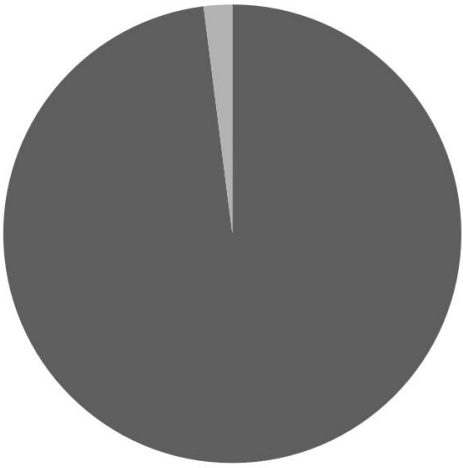

图 1 心情影响调查统计表

因此我们发现, 出现 “当情绪不好时, 遇到的事情都是 不顺的事” 这一情况的概率高达 $98 \%$, 紧接着, 在调查 问卷的下一项, 有这样一个问题: 为什么当你情绪不好
时，也不会觉得遇到的都是不顺的事，我们把出现的原 因总结如下:

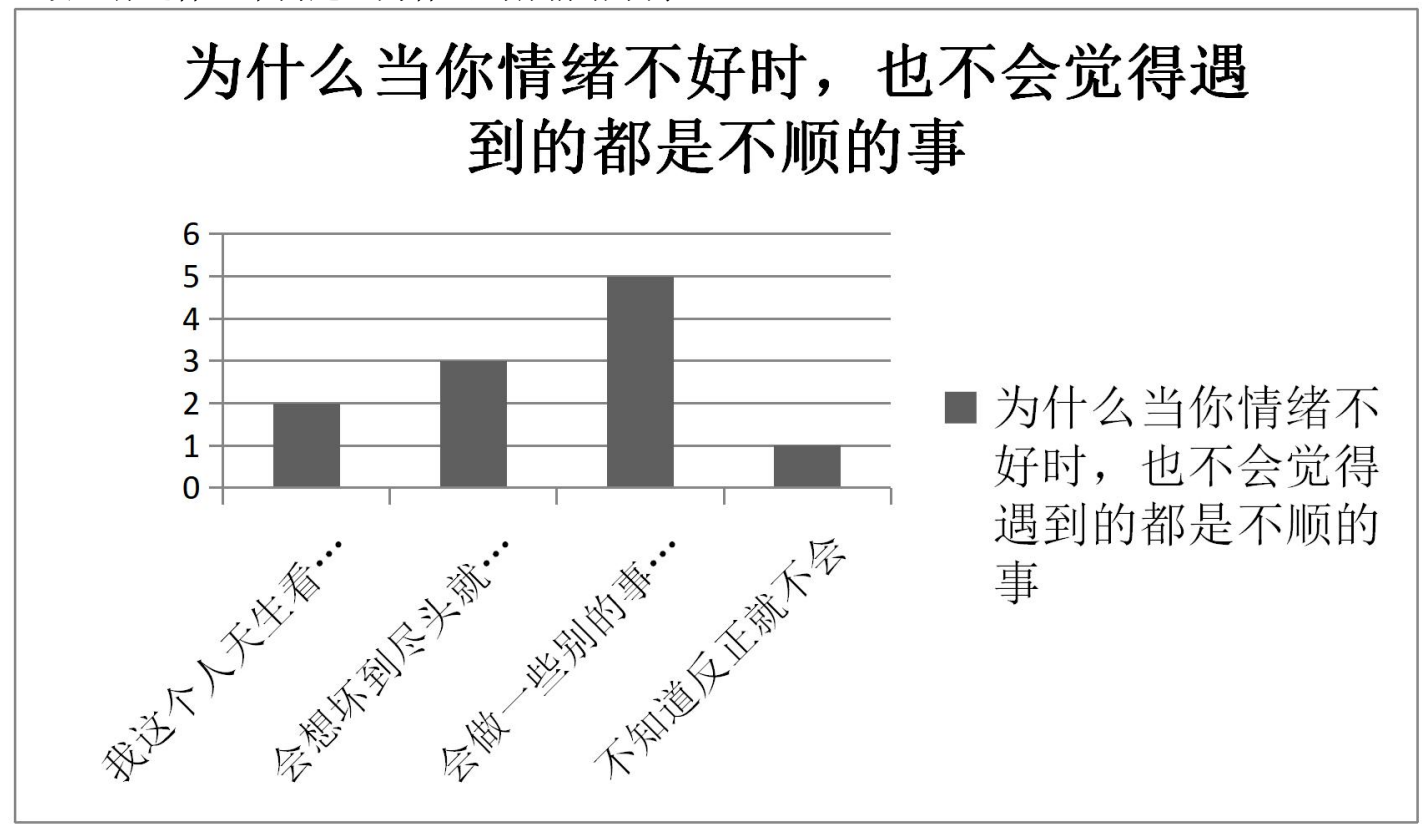

图 2 心情影响与否原因调查统计表

这些数据也就说明了, 所感知的环境会随着心而改变, 当情绪不好时, 所感知的环境也会跟着不好。而从数据 可以看出大部分人能够改变自己所感知的环境的方法其 实都是先改变自己的心态、心情。所以在 EAP 这个体系 中，当帮助咨询者的时候也可以引入这个观念来进行心 理疏导。把这个观念植入咨询者心中就是让他拥有自我 调控的能力。而 EAP 其实就是通过调整情绪、心态甚至 用尽一切方法, 并以此使对象有好的情绪去完成工作。 《道德经》中 “水无为而无不为, 无形而无不行, 处无 为之事, 行不言之教。”【9】无为而无所不为, 这大概 就是道家的攻心之术了。无为便是老子的独创心理学了。 EAP 的目的就是为了提高员工的工作效率, 但人工作的
时候身体累的同时心也会随之感到疲倦。这很多时候是 因为，在做这个工作的时候，心也在关注于这个工作， 心也随之因为你的体力付出导致神经的劳累从而加进心 的疲倦。【10】所以要 “不住心”。什么是不住心，就 是做这个工作的时候，尽心的去做，但心里面不要想做 一个工作而是心里面平静如水, 就像自己在禅坐在平静 的湖面上一样，毫无波澜。当完成工作的时候尽可能的 把已经完成一个工作这个记忆去掉, 就如没完成过任何 工作一样。剩下多少工作不去想，完成了多少不去想。 溪水过而不留, 心中保持平静。在禾田姆中心做过这样 一个实验, 对咨询者建议这个做法, 对这部分建议了的 人做了一个回访结果如下: 


\section{能通过自己领会运用到的人数比例}

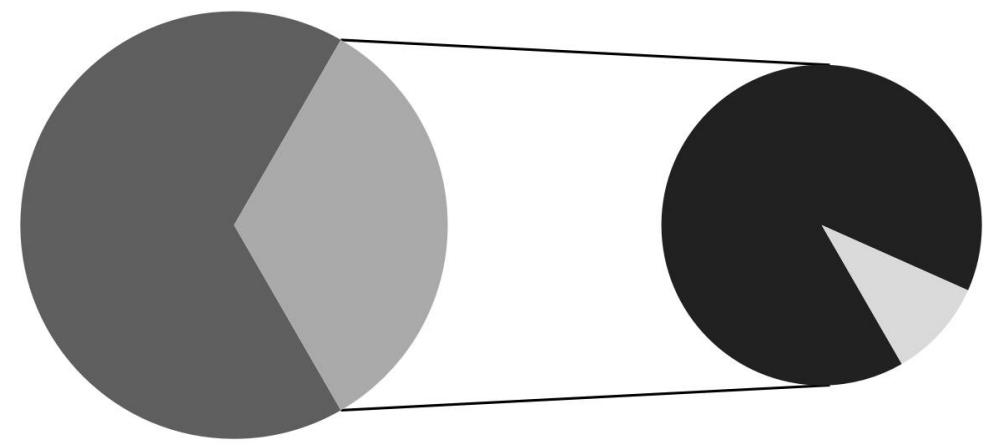

不能

无效果

能

图 3 自我领会人数比例表

从这里可以看出两点第, 第一、很多人靠自己去领悟是 做不到的。第二这个方法效果是有的而且大部分是很明 显的。所以, 说明有需要去把这个方法融入到 EAP 中去, 而且也需要通过和 EAP 的结合去实践这个理念才能收到 成果。

“无所住心”这个词源于佛教经典【11】。而且佛教在 中国, 不能仅仅被当成一种信仰, 还当成一种学术研究 领域。因为 2 就我们今天讨论的心理学 EAP 方面。佛教 中的心理学也可以运用融合, 而且它历史更悠远, 更切 合生活, 佛教历史悠久而且 “出世间不离世间觉”。因此 我个人认为佛教心理学更能与 EAP 结合。
20 世纪 30 年代, 佛教理念逐渐影响着心理指导体系, 许多科学家纷纷加入到佛教心理学的研究总。佛教心理 学的运用逐渐在西方人发达国家形成一种特色化的心理 学管理体系, 且佛教心理学研究也逐渐呈现出扩散化, 逐渐形成一批佛教心理学机构。【12】佛教讲求的 “庄 严国土，利乐有情” 逐渐受到西方发达国家心理学科学 家的重视, 其认为心理调整过程中, 应当从国情、生活 环境进行引导和转化, 基于心理学角度出发, 运用佛教 思想, 逐渐引导患者走出心理疾病, 并实现心理健康管 理逐渐成为西方发达国家最为主要的心理辅导模式。

中国作为佛教的第二故乡，受佛教文化影响的人数可以 说很多, 通过查询找 3 到了一下的一个数据:

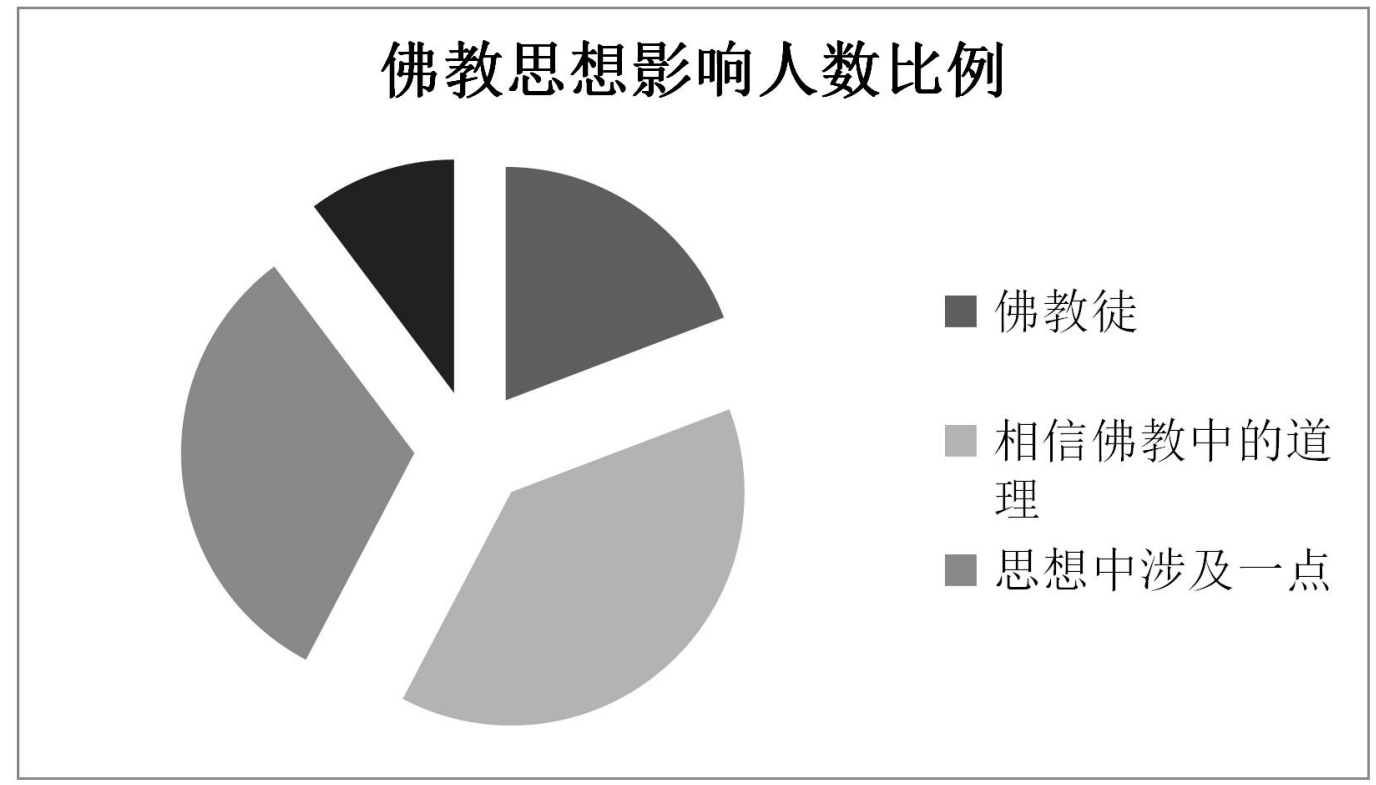

图 4 是否信仰佛教统计表

据《国际传教研究专刊》的统计结果, 世界总人口 75.9427 亿人, 这其中佛教徒就超过 3.6 亿人。所以如果 想让 EAP 在中国可以接地气, 可以更有效的运行, 本人 认为和佛教心理学相结合是个不错的途径。而且佛教心
理学作为中国的一种传统文学, 传统思想, EAP 与之融 合更能得到作为中国人的咨询者的心理认同，知觉认同。 佛教心理学共有十八章, 当中涉及到: 佛教与心理学、 心-—多功能多层次的集起（上、中、下）、自治其心, 
存, 认为二者是构成人体心理的关键因素。【13】其次, 佛教唯识论认为人的意识并不是跟随本体, 而是单独存 在的, 反应周围环境的客观意识。佛罗里的认为, 那些 意识能够控制行为的群体, 往往表现为自身心理承受能 力不足，存在意志不坚定等现象。再次，佛教思想中的 通过般若和禅定等形式进行意识的磨练, 能够实现自身 的升华。相对比来看, 佛罗里的则认为, 意识主要是为 人体执行所服务的, 就如同对于热爱的事情很乐意去享 受在其中一样。而荣格则认为, 意识仅仅是通道, 即表 现在人体意愿与执行之间的具体转化形式。【14】心理 学上的不同这是 EAP 本土化的一大难点与参考。

EAP 本土化发展路径具体如下:

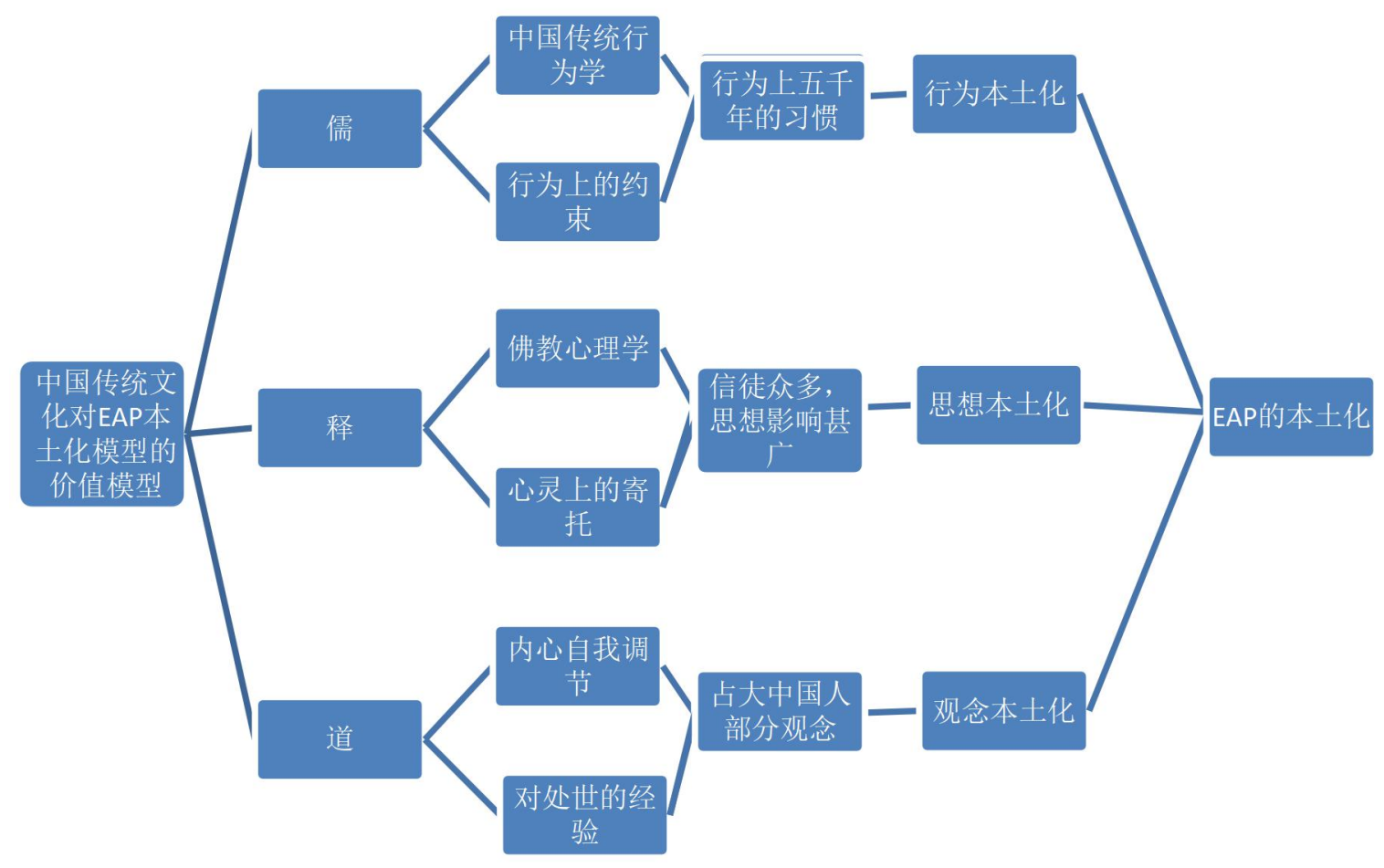

图 5 传统文化对 EAP 本土化模型的价值模型

\section{3. 结论}

\subsection{EAP 中国化的最终目的}

其要知道中国人的思维方式, 要掌握中国人心里接受方 式研究古代文学, 无论是儒家经典心学还是佛教心理学 这些都是不可或缺的。我们中国人重视传统, 重视文化 底蕴, 无时无刻都在受着传统文化的影响, 这就是我们 的中国特色。什么是心理学, 在我看来既是人类经验的 一切现象。“现代心理学之父” 威廉 - 詹姆斯 (Willian James) 就强调心理学的范围应该是包括: 灵魂、宗教经 验等在内的人类经验的一切现象, 定义心理学为 “精神 生活的学科”（1890）。【15】以爱因斯坦为代表的科 学家也不赞同对人类行为的描述加入自然规律。EAP 的 引入过程中, 应当基于我国传统文化底蕴及特点, 企业 运营模式及运营方法进行不断调整。不管是儒家的 “孔
颜之乐” 和 “君子之禄” , 还是道家的 “葟欲”、“无 为”、“守柔”、“不争”, 抑或是佛家的 “众生平 等”、“烦恼即菩提”、“诸行无常” 和 “圆融无碍”, 均反映了我国传统文化之中对于人体心理学的研究精华。

【16】因此，我国企业在引入 EAP 体系过程中，应当充 分融入我国传统文化的影响, 将 “舶来品” 转化为复合 我国国情需求，贴合企业文化发展的有效管理体系，使 EAP 在我国企业得到更好的运用效果。

\section{2. 未来研究}

在中国这样一个有着几千年文化传统的国家，如果要将 EAP 真正落地, 那就不能将 EAP 完全西化, 而应该将中 国传统文化的优秀基因导入 EAP 服务模式中，使中国的 EAP 服务既具有西方 EAP 成套的制度、规范化的操作模 式, 同时又具有中国化的思想和内涵。【17】这就是在 古代文学的基础上研究、改进 EAP 的意义一-EAP 中国 
特色化。所以要通过两方面的研究来促进, EAP 本土化 的发展。第一、加大对传统文化中的心理学思想的研究 与发掘。力求尽所能吧传统文化中能与 EAP 相结合的元 素都能提取出来为 EAP 所用。第二加大对 EAP 内涵的 剖析力度力求找出 EAP 的内涵使其更能融入传统文化中。 第三将两者相结合, 形成一套属于中国人自己的 EAP 体 系。虽然对 EAP 本土化的规划只有三步, 但能完成这三 步也不是一件短时间且简单的事。

希望本文章中对中国传统文化对本土 EAP 模式建设的价 值研究, 能给予 EAP 本土化的发展与探索一些数据上和 理论上的参考。

\section{参考文献}

[1] 360 百 科 [Z] https://baike.so.com/doc/44144574621751.html

[2] 柯瓦奇. 《近代心理学历史导引》 $[\mathrm{M}]$. 商务出版社, 1980 年, $13-75$.

[3] 车文博. 《西方心理学史》 [M]. 浙江教育出版社, 1998 年,33-98.

[4] 波林的. 《实验心理学史》[M]. 商务出版社, 1981 年,23-34.

[5] M.W. 艾森克等（英）. 《心理学———条整合的途径》 (上、下) [M]. 华东师范大学出版, 2001,5-103.

[6] 潘菽. 《中国古代心理学思想》 [M]. 北京出版社. 2018 年 5 月,78-89.

[7] B.R.赫根汉. 《心理学史导论》[M] (上、下) . 华东 师范大学出版社, 2004 年, 13-52.

[8] 周月亮. 《王阳明心学》 [M]. 北京联合出版有限公司, 2018 年 05 月, 20-33.

[9] 李耳. 《道德经全书》 [M]. 光明日报出版社, 2013 年 11,1-39.

[10] 欧文 - 斯通. 《心灵的激情》（上、下） [M]. 中国文 联出版公司, 1986,67-105.

[11] 林崇德、杨治良、黄希庭. 《心理学大辞典》 $[\mathrm{M}]$. 上 海教育出版社,2003 年 34-68.

[12] 陈兵. 《佛教心理学》 $[\mathrm{M}]$. 陕西师范大学出版总社, 2015 年 8 月, 12-116.

[13] 黎黑. 《心理学史》 [M]. 浙江教育出版社,1998 年,2356.

[14] 崔丽娟等. 《心理学是什么》 $[\mathrm{M}]$. 北京大学出版社, 2003 年. $32-65$.

[15] 张春兴. 《现代心理学》 $[\mathrm{M}]$. 上海人民出版社, 1994 年, $57-78$.

[16] 孟昭兰主编. 《普通心理学》 $[\mathrm{M}]$. 北京大学出版社, 2003 年,38-76.

[17] 《国际心理学手册》 (上、下) [Z]. 华东师范大学 出版社, 2002,34-91. 